ISSN 1112-9867

http://www.jfas.info

\title{
PHYSICAL AND MECHANICAL BEHAVIOUR OF A ROLLER COMPACTED CONCRETE REINFORCED WITH POLYPROPYLENE FIBER
}

\author{
A. Benouadah, M. Beddar, and A. Meddah \\ LMMS, Départemnt of Civil engineering, University Mohamed Boudiaf - M' sila, Algeria
}

Received: 15 August 2016 / Accepted: 08 April 2017 / Published online: 01 May 2017

\begin{abstract}
In order to study the behaviour of a roller compacted concrete (RCC) reinforced with polypropylene fiber, six types of RCC were made with different content of fibers $(0,0.5,1$, 1.5, 2 and $2.5 \mathrm{Kg} / \mathrm{m}^{3}$ ). The physical parameters are the density, the workability, the shrinkage and the water absorption. For the mechanical parameters; the performances such as the compressive strength and the tensile strength ( 3 point bending and splitting) has been studied. The results show that the RCC reinforced with fibers present the better performances in terms of strength and physical behaviour. The results obtained show the positive effect of the polypropylene fiber addition on the mechanical strength, which increases about $23 \%$ for the mixture with $1 \mathrm{Kg} / \mathrm{m}^{3}$. For the physical properties, there is a decrease in the density and workability and an improvement in the water absorption proportional with the addition of polypropylene fiber. In addition, we conclude the positive effect of polypropylene fiber on the kinetics and development of the shrinkage. In this study, the best physical and mechanical performance was being observed in the mixture with $1 \mathrm{Kg} / \mathrm{m}^{3}$ of polypropylene.
\end{abstract}

Keywords: Roller compacted concrete, polypropylene fiber, workability, mechanical strength, shrinkage.

Author Correspondence, e-mail: abdelatif.benouadah@yahoo.fr doi: http://dx.doi.org/10.4314/jfas.v9i2.1 


\section{INTRODUCTION}

The field of transport infrastructure is important for economic and socioeconomic development regional, national and international level. The principal element of the transport infrastructure of surface is the solid paving stone, which can be built in order to be soft or rigid. Both construction methods present several advantages and inconvenient in term of traffic loads transferred to the platform [1]. Rigid pavements are made with Portland cement concrete while soft pavements are with asphalt concrete. Although soft pavements are preferred nowadays to the rigid pavements, the researchers continued to evaluate the advantages and the inconvenient of these pavements. The literature tells us that the rigid road built primarily with compacted concrete have a service life longer than asphalt pavements [2]. The use of concrete for the construction of coverings; is now very widespread in the world. The principle of maxing and placing this concrete is very simple; because after determining the amount of water required for mixing: using the principles of geotechnics, it is implemented through a finisher and compacted using roller compactor conventionally used in the production of asphalt. The roller compacted concrete (RCC) thus called because of that installation, offers high resistances and good durability with a speed installation comparable with the asphalt [3].

The use of polypropylene fiber is a useful and economic method in order to improve the characteristics of different concretes. The researchers indicated that the use of this fiber can improve tenacity [4], the bonding strength [5], the impact resistance [6], the tensile strength long-term [7], the behaviour with chipping [8], resistance to abrasion-erosion [9,10], the fire resistance [11,12], the plastic shrinkage [13] and the propagation of the cracks [14]. Several research mentions the advantages and the very broad field of application of the polypropylene fiber, but few research studying the behaviour of these fibers on the special concretes such as RCC. This study aims to understand the physical and mechanical behaviour of a RCC reinforced with polypropylene fiber at fresh and hardened state.

\subsection{Materials and Tests}

The cement used in this study is a Portland cement composes CEM II $42.5 \mathrm{~N}$ manufactured by the Lafarge cement factory located in Algeria according to Standard NF P15-301 [26]. The 
mineralogical composition is presented in the table 1:

Table 1. Mineralogical composition of cement

\begin{tabular}{cc}
\hline Components & Value (\%) \\
\hline C3S & 64 \\
C2S & 18 \\
C3A & 8 \\
C4AF & 10 \\
\hline
\end{tabular}

The RCC is composed of more than $85 \%$ of weight aggregates, for this reason three different fraction (3/8, 8/16 and 16/20) were chosen. The physical and mechanical characteristics of the aggregates are grouped in table 2, the particle size of the gravels and sands are presented in fig 1.

Table 2. Characteristics off different aggregates

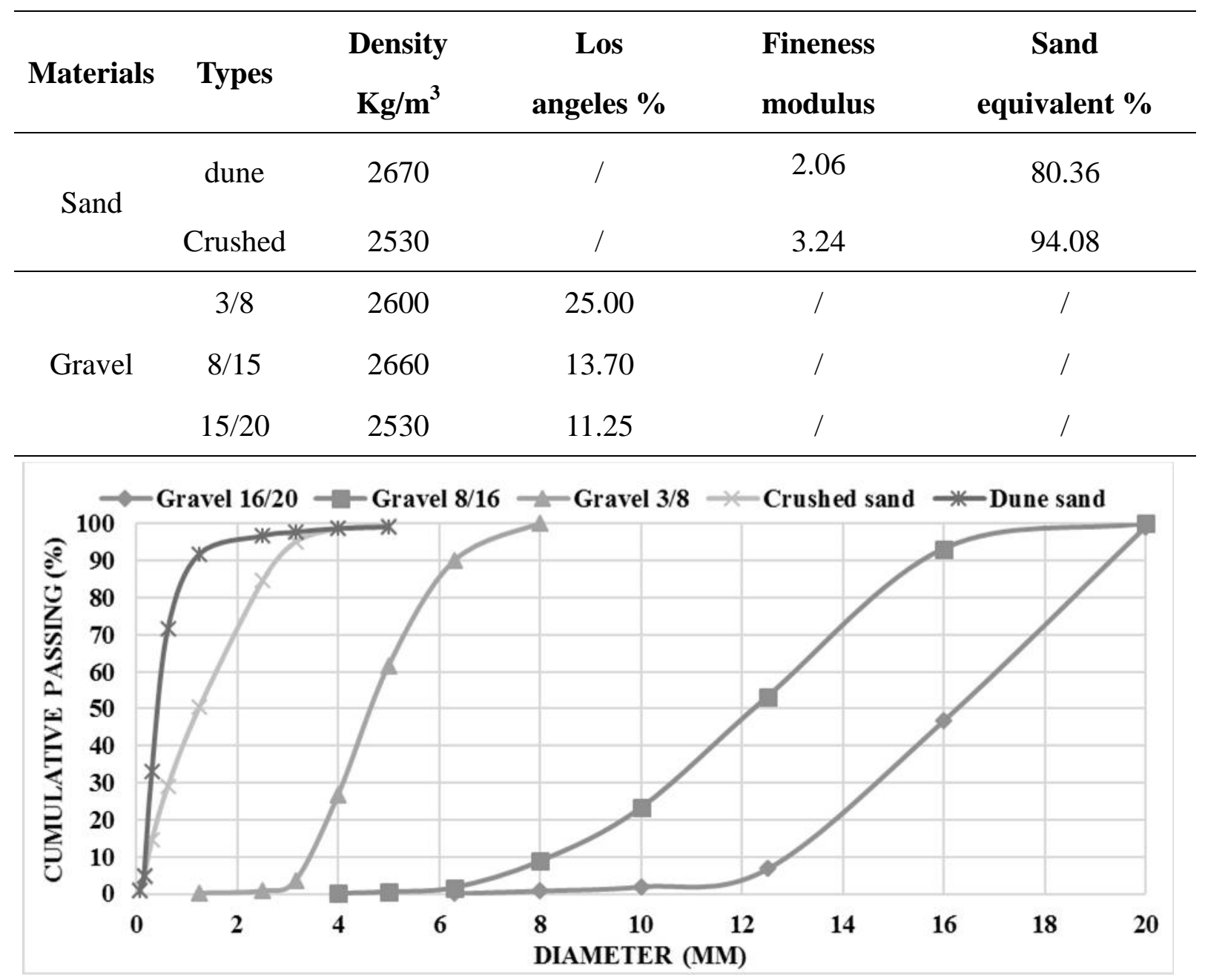

Fig.1. Sieve size of the aggregates 
The fibers used in this study in order to reinforce the roller compacted concrete are polypropylene (PP) fibers of the monofilaments types that are available in the TEKNACHEM company located in Algeria. The different characteristics of these fibers are presented in table 3 .

Table 3. Characteristics off polypropylene fibers

\begin{tabular}{ll}
\hline \multicolumn{1}{c}{ Characteristics } & \multicolumn{1}{c}{ Size } \\
\hline Length & $12 \mathrm{~mm}$ \\
Diameter & 28 microns \\
Density $\left(20^{\circ} \mathrm{C}\right)$ & 0.8 to $1.00 \mathrm{~g} / \mathrm{cm}^{3}$ \\
Degree of fusion & 160 to $170^{\circ} \mathrm{C}$ \\
\hline
\end{tabular}

In order to perform this study and to understand the physical and mechanical behaviour of the RCC reinforced with polypropylene fibers, six various mixtures were made with different content of PP fibers $\left(0,0.5,1,1.5,2\right.$ and $\left.2.5 \mathrm{Kg} / \mathrm{m}^{3}\right)$ according to Banthia et al [15]. The formulation used to make the mixture based on geotechnical principles $[16,17]$. Table 4 shows the designation and proportions of the various RCC.

Table 4. Composition of different mixtures

\begin{tabular}{|c|c|c|c|c|c|c|c|c|}
\hline \multirow{2}{*}{ Mixture } & \multicolumn{3}{|c|}{$\operatorname{Gravel}\left(\mathrm{kg} / \mathrm{m}^{3}\right)$} & \multicolumn{2}{|c|}{ Sand $\left(\mathrm{kg} / \mathbf{m}^{3}\right)$} & \multirow{2}{*}{$\begin{array}{l}\text { Cement } \\
\left(\mathrm{kg} / \mathrm{m}^{3}\right)\end{array}$} & \multirow{2}{*}{$\begin{array}{c}\text { Water } \\
\left(\mathrm{kg} / \mathrm{m}^{3}\right)\end{array}$} & \multirow{2}{*}{$\begin{array}{c}\text { Fiber } \\
\left(\mathrm{Kg} / \mathrm{m}^{3}\right)\end{array}$} \\
\hline & $3 / 8$ & $8 / 16$ & $16 / 20$ & Dune & Crushed & & & \\
\hline $\mathrm{RCC} 0$ & 426.61 & 433.48 & 311.60 & 655.11 & 311. & & 114.405 & 0 \\
\hline RCC0.5 & 426.61 & 433.48 & 311.60 & 655.11 & 311.61 & 295 & 114.405 & 0.5 \\
\hline $\mathrm{RCC} 1$ & 426.61 & 433.48 & 311.60 & 655 & & 29 & 114 & 1.0 \\
\hline $\mathrm{RCC} 1.5$ & 426.61 & 433.48 & 311.60 & 655.11 & 311 & 295 & 114. & 1.5 \\
\hline $\mathrm{RCC} 2$ & 426.61 & 433.48 & 311.60 & 655.11 & 311.61 & 299.38 & 114.405 & 2.0 \\
\hline RCC2.5 & 426.61 & 433.48 & 311.60 & 655.11 & 311.61 & 299.38 & 114.405 & 2.5 \\
\hline
\end{tabular}

The density in a fresh state and the manoeuvrability of the RCC were measured in accordance with the standard ASTM C1170/C1170M-08 [18]. For the compressive strength, specimens of $100 \times 100 \times 100 \mathrm{~mm}$ were made according to standard ASTM C39/C39M-11a [19] to see the development of strength at 7,14 and 28 days. For measured the free shrinkage, prismatic 
samples are necessary according to the standard ASTM C 157/C 157M - 03 [20].

\section{RESULTS AND DISCUSSION}

\subsection{Fresh state}

\subsubsection{Physical properties}

In this part, the density and the compaction time (VEBE) were studied. The results obtained show a reduction in the density of the concrete with the addition of polypropylene fiber, which is explained by the weak density of the fiber that influence the total density of the concrete. For the time of compaction measured with VEBE test, we can see an increase proportional with the addition of polypropylene fiber what confirms the negative effect of PP fiber on the workability of the concrete [21]. The reduction in workability with addition of PP fiber can be explained by the rate of absorption of the fiber, which is probably due to the creation of a fiber network that interferes with water circulation and makes the concrete drier.

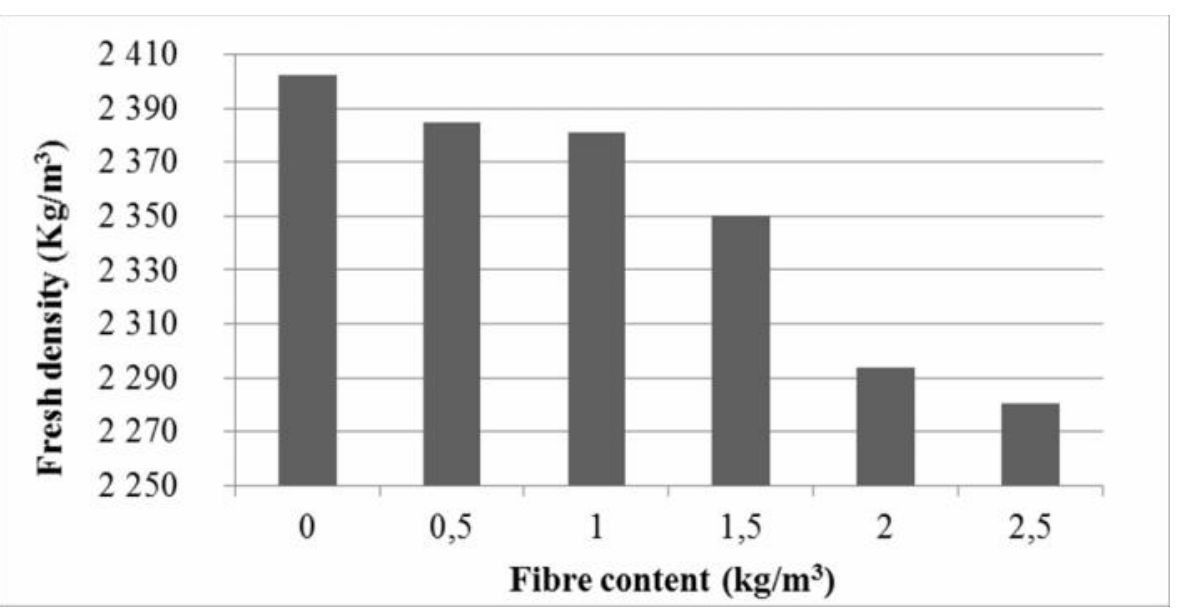

Fig.2. Variation of the density in a fresh state of the various types of RCC 


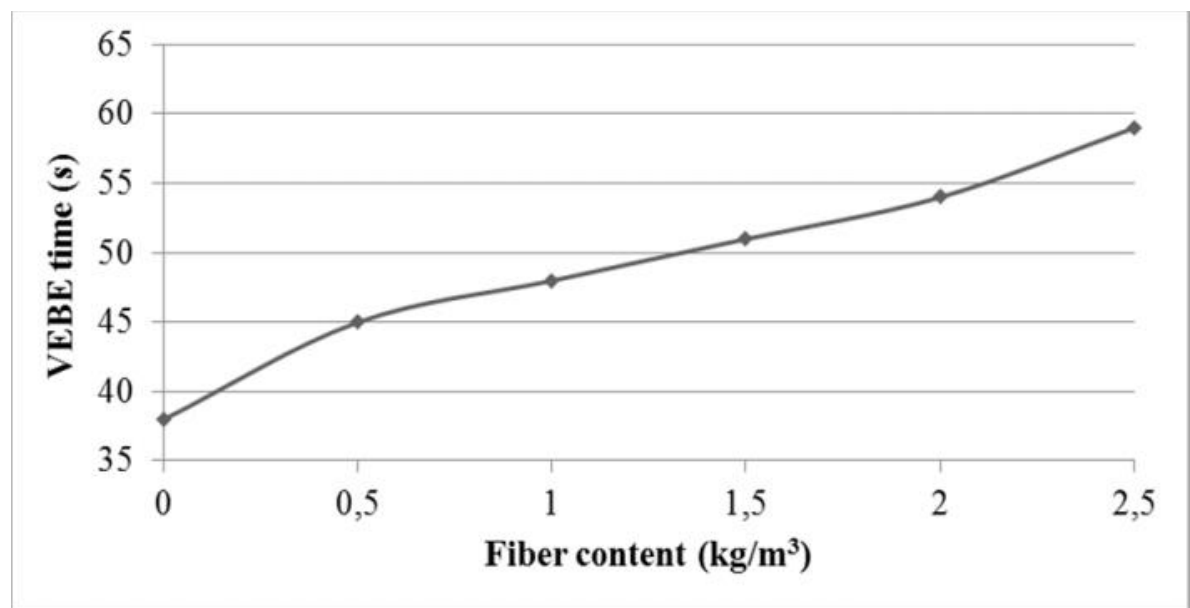

Fig.3. Variation of the workability according to VEBE time of the different types of RCC

\subsection{Hardened state}

\subsubsection{Mechanical properties}

In a hardened state, the roller compacted concrete counts two principal parameters, which are the compressive strength and the tensile strength (three-point bending and splitting).

For the compressive strength, we can see from the fig 4 that the effect of polypropylene fiber is beneficial for the 0.5 and $1 \mathrm{Kg}$ per $\mathrm{m}^{3}$ concrete [22], Topçu and Canbaz [23] showed that the fibers could reduce the formation and the development of the cracks, and thus lead to the increase in compressive strength. Beyond $1 \mathrm{Kg}$ per $\mathrm{m} 3$, the loss in resistance is noted. This reduction is due to a fiber excess in the mixture, which causes reduction of strength.

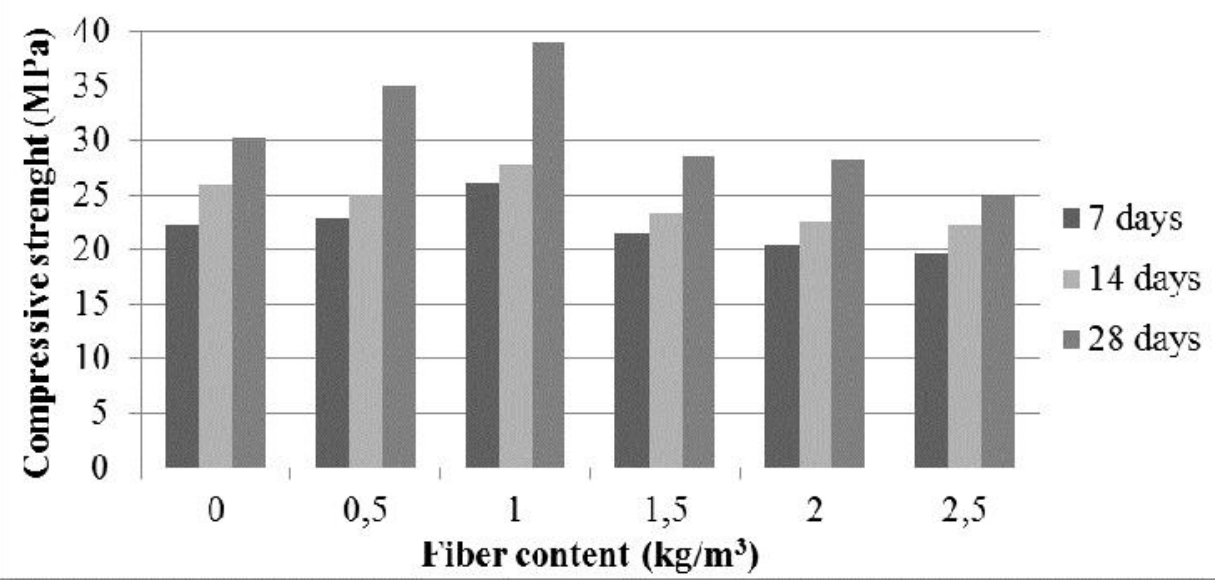

Fig.4. Variation of the compressive strength of various types of RCC at 7, 14 and 28 days 


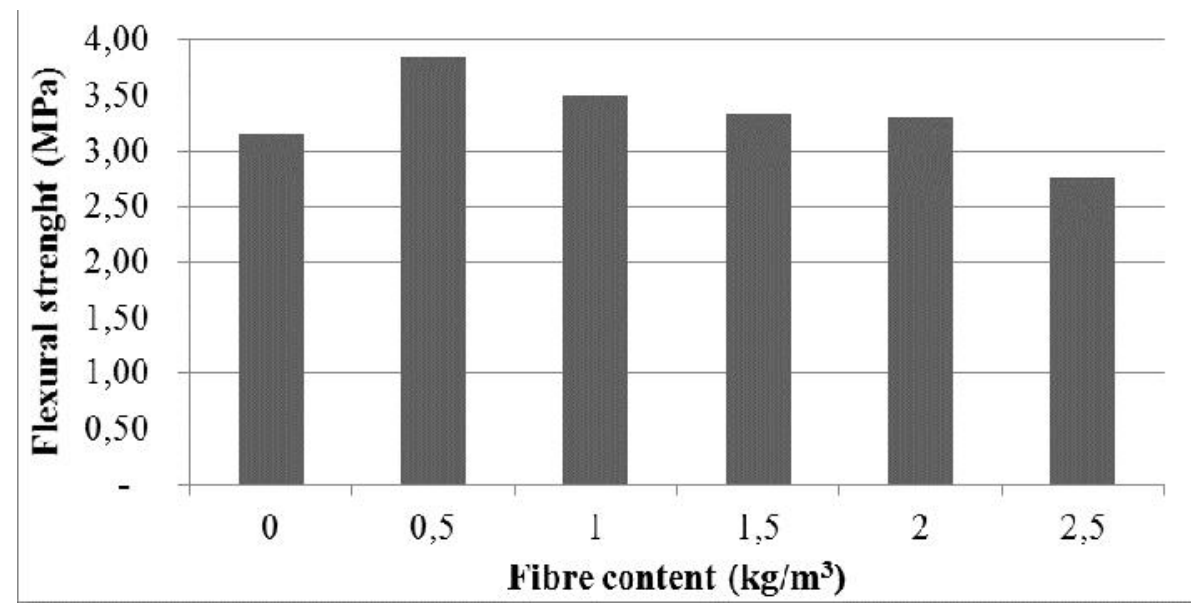

Fig.5. Variation in the tensile strength by bending of the various types of RCC

According to fig 6, which shows the variation of the tensile strength by splitting of the various types of RCC; we can see that the use of polypropylene fiber in RCC with $0.5,1,1.5$ and $2 \mathrm{Kg} / \mathrm{m}^{3}$ has a positives effect on the tensile strength by splitting. An increase with $32 \%$ from the RCC2 compared to the RCC0 can be observed.

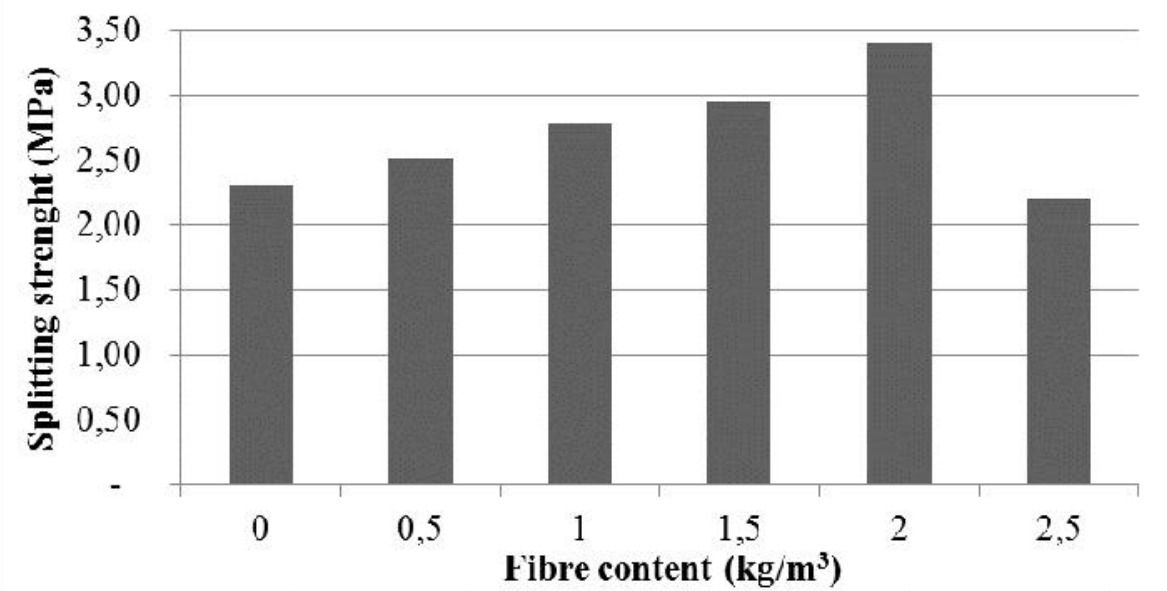

Fig.6. Variation of the tensile strength by splitting of the various types of RCC

Furthermore, a decrease in the tensile strength by splitting was been observed for RCC 2.5 with $5 \%$ compared to RCC0, which is due to an excess of the fiber proportioning (exceeded optimal quantity).

S. Kakooei et al. [24] reported that the increase in the mechanical strength in the concretes reinforced with polypropylene fiber is due to the provision of the fiber, which is in width compared to the cracks creating bridges of connection that make the concrete more resistant.

\subsection{Physical properties}




\subsubsection{Shrinkage}

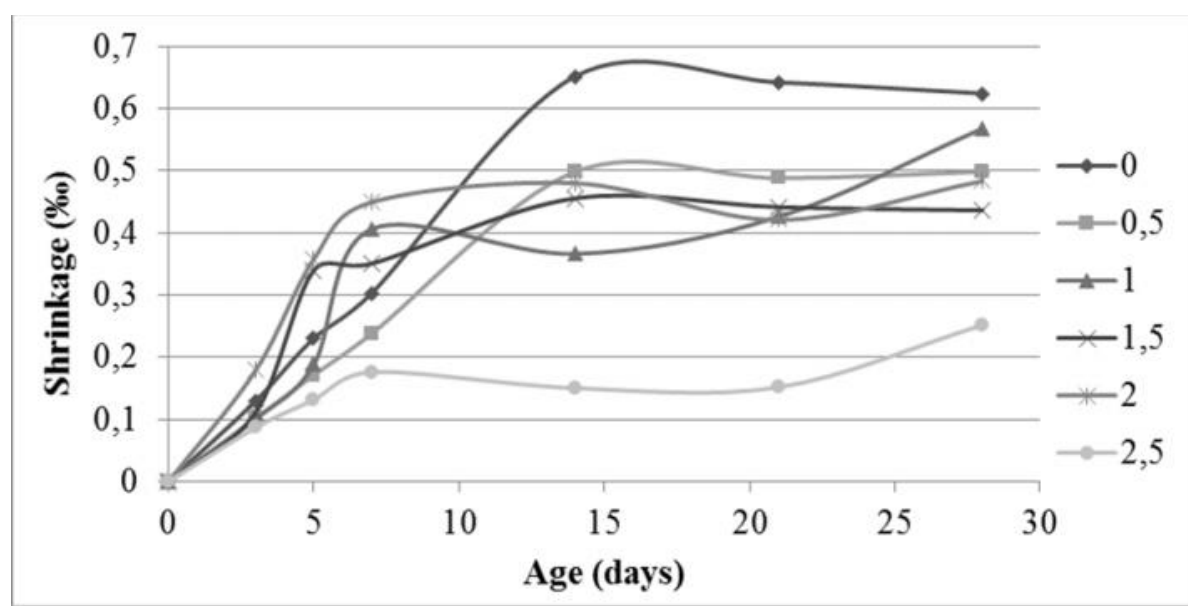

Fig.7. Evolution of the shrinkage of the various types of RCC

Fig 7 show the results of the shrinkage of the various concretes $(0,0.5,1,1.5,2$ and $2.5 \mathrm{Kg}$ per $\mathrm{m}^{3}$ ). We can conclude according to this graph that the shrinkage of the reference mixture without polypropylene fiber is significant compared to the mixture containers polypropylene fibers. RCC2.5 presents a slight shrinkage compared to the other concretes. R.D. Tolêdo Filho et al. [25] indicates that the polypropylene fiber addition reduces the shrinkage considerably which is in coordination with other research.

It is also noted that RCC0 stabilizes at 14 days whereas the mixtures containing polypropylene fiber are stabilized at 7 days from these results it can be concluded that PP fibers have a seam effect on the development of micro-cracks at early ages, which decreases the rate of shrinkage of reinforced concrete with fibers.

The decrease for the shrinkage in mixtures with polypropylene fiber can be explained by the creation of fiber networks, which produce a seaming effect, this allows the RCC with fiber to have a low shrinkage rate.

\subsubsection{Absorption}




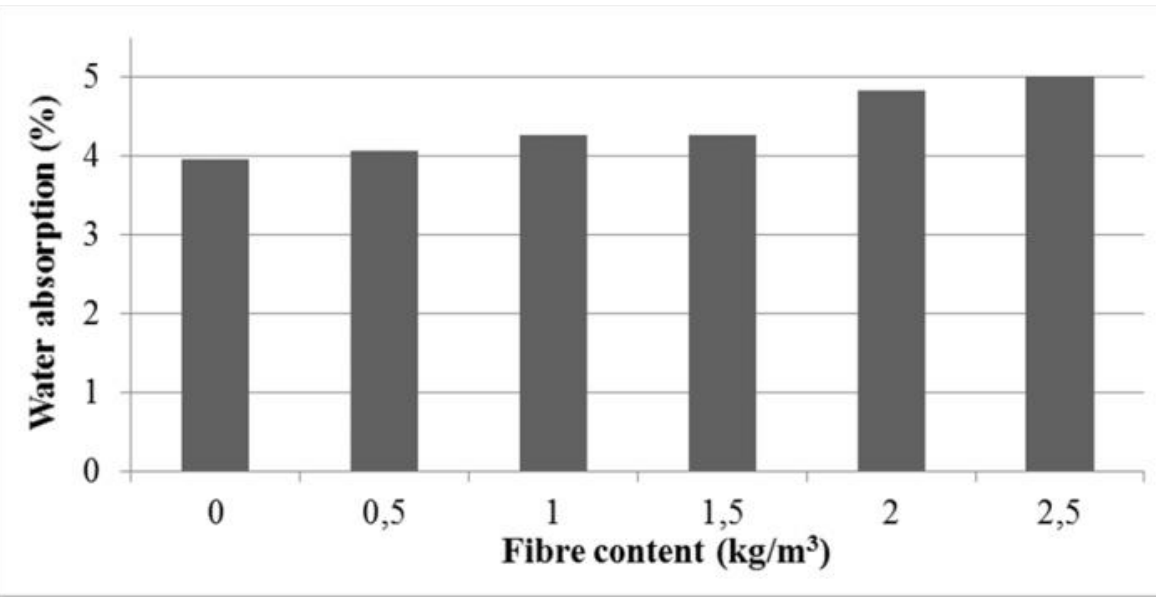

Fig.8. Variation of the degree of absorption of the various concretes

Fig 8 shows water absorption of various concretes. We can see according to the results that the water absorption is proportionally with polypropylene fibers content with $(3 \%, 7 \%, 8 \%$, $19 \%$ and $21 \%)$ for $\left(0.5,1,1.5,2\right.$ and $2.5 \mathrm{Kg}$ per $\left.\mathrm{m}^{3}\right)$ respectively.

This result proves the negative effect of polypropylene fiber on water absorption especially at

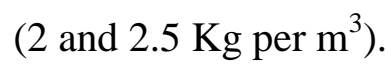

\subsection{Visual appearance under optical microscope}

In this part, we wanted to see the incorporation of polypropylene fibers on a microscopic scale. For that, we prepared samples of RCC and other of RCC reinforced with PP, then we made them pass from an optical microscopic. The two pictures obtained from the optical microscope represents the RCC without PP and the RCC with PP are presented in fig 9.

We can see from the picture (A) the presence of a fiber that fits perfectly in the cement matrix. The second picture (B) shows RCC without fiber.

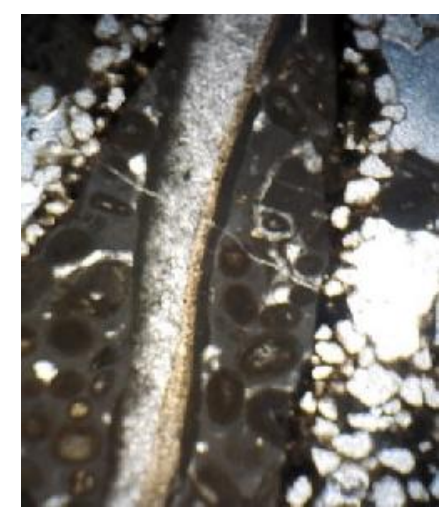

(A)

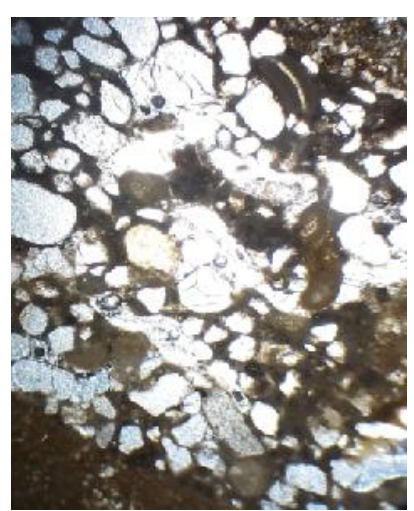

(B)

Fig.9. Microscopic photography: (A) RCC with PP fiber, (B) RCC without PP fiber 


\section{CONCLUSION}

The purpose of this study is principal to understand the behaviour of a RCC reinforced with polypropylene fibers. The conclusions tired from this study are:

The addition of fibers in RCC reduces the density of the concrete, which can be explained by the weak density of the PP fibers.

The workability of the RCC fell with the addition of fibers. This phenomenon is current in the concretes reinforced with fiber; several research found the same thing. The reduction of workability is explained by the rate of absorption of synthetic fibers, which is probably due to the creation of a fiber network that interferes with water circulation.

The incorporation of polypropylene fibers in a roller compacted concrete gave satisfactory results in term of mechanical strength. The PP fibers were located in width compared to the crack what improved the arrow of the concrete.

The behaviour of the RCC fiber against the shrinkage is remarkable. More the content of fiber is high more the shrinkage decreases. We can explain the effect of fibers on the shrinkage by the phenomenon of seam of the cracks, which prevents the development of the free shrinkage. The water absorption of concretes is clearly indicating that the PP fibers have a detrimental effect on the absorption of the concretes; the reduction of the workability consolidates these results.

The visual aspect of the concretes observed under optical microscope shows the positioning of the polypropylene fibers clearly in the matrix of the roller compacted concrete. It is observed that the cement paste has well wrapped the PP fiber, also we can see a segregation caused probably by the presence of PP fiber.

After studying possible incorporation of polypropylene fibers in a roller compacted concrete, it can be concluded from this study that the incorporation of $1 \mathrm{Kg}$ per $\mathrm{m}^{3}$ gives results conclude at the physical and mechanical properties.

\section{ACKNOWLEDGEMENTS}

TEKNACHEM are gratefully acknowledged for providing polypropylene fibres. 


\section{REFERENCES}

[1] Yoder EJ and Witczak MW (1975) Principles of Pavement Design, 2nd edition. Wiley, Hoboken, NJ, USA.

[2] Saucier F., Cormier B. et Duchesne C., (1995), Introduction au dimensionnement et à la construction des chaussées en béton de ciment, Centre de recherche interuniversitaire sur le béton, CRIB, Département de génie civil, Université Laval, Canada, pagination multiple.

[3] ACI (American Concrete Institute) (1995) Report on Roller- Compacted Concrete Pavements. ACI, Detroit, MI, USA, (reapproved 2001), Report ACI 325.10R-95, pp. 1-31.

[4] Ren Z, Hu P, Zou Y. Experimental study on flexural toughness of steel polypropylene fiber reinforced concrete. In: International conference on civil engineering and building materials, CEBM]. Scopus, Trans Tech Publication; 2011.

[5] Buyukozturk O, Tuakta C. Conceptual model prediction of FRP-concrete bond strength under moisture cycles. J Compos Constr 2011; 15:743-56.

[6] Badr Atef, Ashour Ashraf F, Platten Andrew K. Statistical variations in impact resistance of polypropylene fiber-reinforced concrete. Int J Impact Eng 2006; 32:1907-20.

[7] Yao Wu, Zhong Wenhui. Effect of polypropylene fibers on the long-term tensile strength of concrete. J Wuhan Univ Technol-Mater Sci Ed 2007; 22.

[8] Yao Wu. Flexural strength and behaviour of polypropylene fiber reinforced concrete beams. J Wuhan Univ Technol-Master Sci Ed 2002; 2 (17):54-7.

[9] Horszczaruk EK. Hydro-abrasive erosion of high performance fiber-reinforced concrete. In: 17th International conference on wear of materials 2009; 267:110-5.

[10] Grdic Zoran J, ToplicicCurcic Gordana A, Ristic Nenad S, Despotovic Iva M. Abrasion resistance of concrete micro-reinforced with polypropylene fibers.

Constr Build Mater 2012; 27:305-12.

[11] Ali Behnood, Masoud Ghandehari. Comparison of compressive and splitting tensile. Fire Saf J 2009; 44:1015-22.

[12] Rodrigues JoaoPauoloC, Luis Laim, Antonio MouraCorreia. Behaviour of fiber concrete columns in fire. Compos Struct 2010; 92:1263-8. 
[13] Sivakumar A, Santhanam Manu. A quantitative study on the plastic shrinkage cracking in high strength hybrid fiber reinforced concrete. Cement Concr

Compos 2007; 29:575-81.

[14] Richardson AE. Bond characteristics of structural polypropylene fibers in concrete with regard to post-crack strength and durable design. Struct Surv

$2005 ; 23: 210-30$.

[15] Banthia N, Gupta R. Influence of polypropylene fiber geometry on plastic shrinkage cracking in concrete. Cement Concrete Res 2006; 36:1263-7.

[16] American Society for Testing and Materials (ASTM) D1557-07, 2007. Laboratory Compaction Characteristics of Soil Using Modified Effort Standards (West Conshohocken, PA, USA).

[17] Marchand, J., Gagné, R., Ouellet, E., Lepage, S., 1997. Mixture Proportioning of Roller Compacted Concrete e a Review, pp. 457e487. Concrete Technology Special Publication SP-171e22.

[18] American Society for Testing and Materials (ASTM) C1170/C1170M-08, 2008. Standard Test Method for Determining Consistency and Density of Roller compacted Concrete Using a Vibrating Table (West Conshohocken, Pennsylvania, USA).

[19] American Society for Testing and Materials (ASTM) C39/C39M-11a, 2011. Standard Test Method for Compressive Strength of Cylindrical Concrete Specimens. In: Annual Book of ASTM Standards (West Conshohocken, Pennsylvania, USA).

[20] American Society for Testing and Materials (ASTM) C 157/C 157M - 03, 2003. Standard Test Method for Length Change of Hardened Hydraulic-Cement Mortar and Concrete. In: Annual Book of ASTM Standards (West Conshohocken, Pennsylvania, USA).

[21] Yap SP, Alengaram UJ, Jumaat MZ. Enhancement of mechanical properties in polypropylene and nylon fibre reinforcedoil palm shellconcrete. Mater Des 2013; 43:1034-41.

[22] P.S. Songa, S. Hwangb, B.C. Sheub "Strength properties of nylon- and polypropylene-fiber-reinforced concretes" Cement and Concrete Research 35 (2005) 15461550 June 2004 
[23] Topçu B, Canbaz M. Effect of different fibers on the mechanical properties of concrete containing fly ash. Constr Build Mater 2007; 21:1486-91.

[24] S. Kakooei et al. The effects of polypropylene fibers on the properties of reinforced concrete structures. Construction and Building Materials 27 (2012) 73-77

[25] R.D. Tolêdo Filho et al. Effect of low modulus sisal and polypropylene fiber on the free and restrained shrinkage of mortars at early age. Cement and Concrete Research 29(10):1597 1604 - October 1999.

[26] NF P15-301. Liant hydraulique, Ciment courant-composition, spécification et critères de conformité, 1994.

\section{How to cite this article:}

Benouadah A, Beddar M, and Meddah A. Physical and mechanical behaviour of a roller compacted concrete reinforced with polypropylene fiber. J. Fundam. Appl. Sci., 2017, 9(2), 623-635. 